\title{
Gender Differences and Related Factors Affecting Online Gaming Addiction Among Taiwanese Adolescents
}

\author{
Chih-Hung Ko, MD, * Ju-Yu Yen, MD, *广 Cheng-Chung Chen, MD, PhD, * Sue-Huei Chen, PhD, t \\ and Cheng-Fang Yen, $M D, P h D^{*}$
}

\begin{abstract}
The aim of this study was to evaluate the extent to which gender and other factors predict the severity of online gaming addiction among Taiwanese adolescents. A total of 395 junior high school students were recruited for evaluation of their experiences playing online games. Severity of addiction, behavioral characteristics, number of stressors, and level of satisfaction with daily life were compared between males and females who had previously played online games. Multiple regression analysis was used to explore gender differences in the relationships between severity of online gaming addiction and a number of variables. This study found that subjects who had previously played online games were predominantly male. Gender differences were also found in the severity of online gaming addiction and motives for playing. Older age, lower self-esteem, and lower satisfaction with daily life were associated with more severe addiction among males, but not among females. Special strategies accounting for gender differences must be implemented to prevent adolescents with risk factors from becoming addicted to online gaming.
\end{abstract}

Key Words: Addiction, adolescent, gender difference, Internet use.

( $J$ Nerv Ment Dis 2005;193: 273-277)

In recent decades, Internet use has become a part of modern daily life. Adolescents in Taiwan have been encouraged to use the Internet to increase academic competitiveness. However, Lin and Tsai (2002) reported that $11.7 \%$ of high school students have developed addiction to Internet use, which can impair academic performance, psychological well-being, and interaction with peers and family members (Whang et al.,

\footnotetext{
*Department of Psychiatry, Kaohsiung Medical University, Kaohsiung, Taiwan; †Department of Psychiatry, Kaohsiung Municipal Hsiao-Kang Hospital, Kaohsiung, Taiwan; and \$Department of Psychology, National Taiwan University, Taipei, Taiwan.

Send reprint requests to Cheng-Fang Yen, MD, PhD, Department of Psychiatry, Kaohsiung Medical University, Chung-Ho Memorial Hospital, 100 Tzyou 1st Rd., Kaohsiung City, Taiwan 807.

Copyright (C) 2005 by Lippincott Williams \& Wilkins

ISSN: 0022-3018/05/19304-0273
}

DOI: $10.1097 / 01 . n m d .0000158373 .85150 .57$
2003). Adolescent psychosocial development may also be impeded. Because online gaming is the most popular Internet activity among Taiwanese adolescents, it is important to explore the behavioral characteristics of online gaming among adolescents to form the basis of preventive and interventional strategies.

Several studies have aimed to develop diagnostic criteria for Internet addiction. The distinguishing characteristics of Internet addiction examined in previous studies include preoccupation, loss of control, tolerance, withdrawal, craving, impairment of function, and reduced decision-making ability (Table 1). These distinguishing characteristics are similar to those of substance dependence and impulse control disorder in DSM-IV (American Psychiatric Association, 1994). Further study is necessary to determine the essential characteristics of Internet addiction and establish definitive criteria of Internet addiction.

The most promising route to effective strategies for the prevention of addictive behavior among adolescents is through a risk-focused approach, which requires the identification of factors related to addictive behaviors (Hawkins et al., 1992). Previous studies have revealed that low selfesteem (Emery et al., 1993), a low level of life satisfaction (Jenks, 1994; Zullig et al., 2001), and exposure to stress (Kreek and Koob, 1998) increase the risk for drug addiction. However, the relationship between addiction to online gaming and self-esteem, life satisfaction, and stressors in daily life has seldom been investigated with regard to adolescents.

Gender differences have been found in the behavioral patterns (Boyle and Offord, 1986) and related factors of addictive behaviors (Bukstein et al., 1992). Substance abuse and dependence are reportedly more likely in males than in females (Coffey et al., 2003; Dawson and Archer, 1992; Wilsnack et al., 2000). A similar result has been reported with reference to adolescents. However, gender differences of drug addiction on adolescents have become less obvious overtime (Wallace et al., 2003).

Gender differences in motivation for substances abuse have also been frequently reported. For example, females are more likely to use illicit drugs for self-medication or to cope 
TABLE 1. Distinguishing Characteristics of Internet Addiction

A maladaptive pattern of Internet use, leading to clinically significant impairment or distress, occurring at any time within the same 3 -mo period

1. Preoccupation with Internet activities

2. Recurrent failure to resist the impulse to use the Internet

3. Tolerance: a marked increase in the duration of Internet use needed to achieve satisfaction.

4. Withdrawal

a. Symptoms of dysphoric mood, anxiety, irritability, and boredom after several days without Internet activity

b. Use of Internet to relieve or avoid withdrawal symptoms

5. Use of Internet for a period of time longer than intended

6. Persistent desire and/or unsuccessful attempts to cut down or reduce Internet use

7. Excessive time spent on Internet activities and to leave the Internet

8. Excessive effort spent on activities necessary to obtain access to the Internet

9. Recurrent Internet use resulting in a failure to fulfill major role obligations at school, home, and social relationship

10. Continued Internet use despite knowledge of having a persistent or recurrent physical or psychological problem likely to have been caused or exacerbated by Internet use

with depression and stressful life events (Griffin et al., 1989; Inciardi et al., 1993). Self-confidence, social interaction, and rebellion are reportedly associated with female smoking, whereas social insecurity is associated with male smoking (Clayton, 1991). In addition, whereas males with strong attachments to peers report heavier use of substances, stronger family bonds are associated with reduced use of all substances except cigarettes in females (Ensminger et al., 1984). However, the results of previous studies of gender differences in Internet addiction are still a matter of controversy (Greenfield, 1999; Lin and Tsai, 2002). Meanwhile, gender differences in motivation for playing online games have seldom been examined. Further studies of the issue of gender differences in behavioral characteristics of online gaming addiction are necessary and are of great importance.

The aims of the present study were to (1) evaluate gender differences in the behavioral characteristics, motives, and severity of online gaming addiction among adolescents; (2) evaluate gender differences in self-esteem, daily life satisfaction, and stressors among adolescents who play online games; and (3) compare gender differences in the extent to which severity of online gaming addiction is predicted by age, self-esteem, daily life satisfaction, number of stressors, and gaming location.

\section{METHODS}

\section{Participants}

A total of 395 adolescents (170 males and 225 females) were recruited for the present study from a junior high school located in central Kaohsiung, the largest city in southern Taiwan. Their online gaming experiences were initially screened by self-reported questionnaires. Two hundred twenty-one adolescents $(55.9 \%, 139$ males and 82 females) reported that they had played online games. The mean age of subjects was 13.8 years ( $\mathrm{SD}=0.7$ years; range, $13-15$ years). Those who had previously played online games were further assessed for behavioral characteristics and risk factors related to addiction to online gaming.

\section{Survey Instruments}

\section{Chinese Internet Addiction Scale}

The Chinese Internet Addiction Scale (CIAS; Chen et al., 2003) contains 26 items on four-point Likert scale that assess five dimensions of Internet-related problems, including compulsive use, withdrawal, tolerance, interpersonal relationships, health, and time management. The internal reliability of the scale and the subscales in the original study ranges from 0.79 to 0.93 . Correlation analyses yield a significant positive correlation of total scale and subscale scores of the CIAS with the hours spent weekly on Internet activity (Chen et al., 2003). For the purpose of the present study, the colloquial expressions of CIAS were modified to assess subjects' online gaming experiences, with the Cronbach $\alpha$ 0.96 . Higher CIAS scores indicated increased severity of addiction to online gaming.

\section{Rosenberg Self-Esteem Scale}

The Rosenberg Self-Esteem Scale (RSES) contains 10 four-point items that assess subjects' self-esteem, with good reliability and construct validity (Rosenberg, 1965). The higher the RSES score, the higher the level of the subjects' self-esteem. The Cronbach $\alpha$ in the present study was 0.62 .

\section{Questionnaire for Playing Online Games}

The Questionnaire for Playing Online Games (QPOG) was designed to assess the age at which subjects initially began playing online games, time and money spent playing online games, and location at which subjects play online games. Various motives for playing online games, including feelings of achievement, making social contacts, relief from negative emotions, excitement, and passing time are also assessed.

Self-administered questionnaires measure subjects' daily life satisfaction and total numbers of stressors encountered in daily life. Higher scores indicate increased daily life satisfaction. 


\section{Procedures and Statistical Analysis}

Informed consent was obtained from all subjects before assessment. All subjects completed the CIAS, RSES, and QPOG after receiving instructions from researchers. Gender differences in behavioral characteristics of online gaming, CIAS and RSES scores, total numbers of stressors, and levels of daily life satisfaction were compared by $t$ test and $\chi^{2}$ test. Multiple regression models were further used to evaluate gender differences in the predictive model between severity of addiction to online gaming and other variables, including age, self-esteem, daily life satisfaction, total number of stressors, and online gaming location. A $p$ value less than .05 was considered statistically significant.

\section{RESULTS}

\section{Characteristics of Online Game Players by Gender}

The proportion of subjects who had previously played online games was significantly higher among male adolescents $(81.8 \%)$ than among females $\left(36.4 \% ; \chi^{2}=80.7 ; p<\right.$ $.001)$. Comparisons of behavioral characteristics of online gaming, CIAS and RSES scores, total numbers of stressors, and level of daily life satisfaction between male and female online gamers are shown in Tables 2 and 3. Males had higher scores on CIAS and its five dimensions than females, which indicated that males were more addicted to online gaming than females. More males than females spent 10 or more hours per week playing online games. More males than females played online games to pursue feelings of achievement and to make friends, whereas more females than males played online games for the purpose of passing time. No gender differences were found in money spent, age at which subjects initially started playing online games, or proportion of time spent playing online games at home versus other locations. There were also no gender differences in age, total numbers of stressors, level of daily life satisfaction, or RSES scores.

\section{Other Factors Related to Online Gaming Addiction}

As shown in Table 4, the results of multiple regression analyses indicate that the general model was statistically significant for males $\left(F_{5,133}=6.794 ; p<.001\right)$, but not for females $\left(F_{5,76}=1.408 ; p=.231\right)$. For males, $R^{2}$ for overall model indicated that approximately $20.5 \%$ of the variance of online gaming addiction was accounted for by five independent variables. Older age, lower self-esteem, and lower daily life satisfaction were associated with more severe online gaming addiction in males. In females, however, none of the five variables was significantly associated with online gaming addiction, and all five variables together could account for only $8.5 \%$ of the variance.

\section{DISCUSSION}

The present study revealed that more male adolescents had played online games and that online gaming addiction is more likely among males than among females, which is consistent with the findings of Lin and Tsai (2002). Two possible models of explanations can account for these differences. First, we found that more males than females play online games to pursue feelings of achievement and make social contacts. Previous studies have found that more males than females engage in drug use for social bonding and to enhance self-esteem (Moon et al., 1999; Newcomb et al., 1988). Online gaming can enhance self-image by offering opportunities to interact with others sharing the same interest and to pursue a strong and smart self-identification, both of which increase the risk of addiction among males. Second,

TABLE 2. Gender Differences in Age, Stressors, Daily Life Satisfaction, Self-Esteem, and Addiction to Online Gaming

\begin{tabular}{lrrrrr}
\hline & \multicolumn{1}{c}{ Male } & & Female & & \\
\cline { 2 - 2 } & Mean (SD) & & Mean (SD) & t & p \\
\hline Age, y & $13.8(0.7)$ & & $13.7(0.7)$ & -0.721 & .472 \\
Total numbers of stressors & $1.5(2.3)$ & & $1.8(1.5)$ & 0.954 & .341 \\
Daily life satisfaction & $3.8(0.8)$ & & $3.9(0.9)$ & 0.692 & .490 \\
RSES scores & $28.6(4.4)$ & & $28.6(3.8)$ & 0.088 & .930 \\
Age started online gaming, y & $11.3(1.3)$ & & $11.6(1.2)$ & 1.591 & .113 \\
CIAS scores & $2.0(0.6)$ & & $1.7(0.6)$ & -3.857 & $<.001$ \\
Compulsive symptoms & $1.9(0.7)$ & & $1.6(0.7)$ & -3.803 & $<.001$ \\
Withdrawal symptoms & $2.1(0.8)$ & & $1.8(0.8)$ & -2.719 & .007 \\
Tolerance symptoms & $2.1(0.6)$ & & $1.8(0.7)$ & -2.823 & .005 \\
Interpersonal and health problems & $1.9(0.6)$ & & $1.6(0.7)$ & -3.141 & .002 \\
Time management problems & $1.8(0.6)$ & & $1.5(0.6)$ & -3.953 & $<.001$ \\
\hline
\end{tabular}


TABLE 3. Gender Differences in Behavioral Characteristics of and Motives for Online Gaming

\begin{tabular}{|c|c|c|c|c|}
\hline & Male & Female & & \\
\hline & $(N=139)$ & $(N=82)$ & & \\
\hline & $N(\%)$ & $N(\%)$ & $\chi^{2}$ & $p$ \\
\hline \multicolumn{5}{|l|}{ Weekly time spent gaming online } \\
\hline $10 \mathrm{~h}$ or more & $43(30.9)$ & $13(15.9)$ & 6.201 & .013 \\
\hline$<0 \mathrm{~h}$ & $96(69.1)$ & $69(84.1)$ & & \\
\hline \multicolumn{5}{|c|}{ Monthly money spent gaming online } \\
\hline 500 NT\$ or more & $29(20.9)$ & $17(20.7)$ & 0.001 & .981 \\
\hline$<500$ NT\$ & $110(79.1)$ & $65(79.3)$ & & \\
\hline Gaming online at home & $81(58.3)$ & $55(67.1)$ & 1.687 & .194 \\
\hline \multicolumn{5}{|l|}{ Motives for gaming online } \\
\hline Feelings of achievement & $66(47.5)$ & $24(29.3)$ & 7.088 & .008 \\
\hline Making friends & $82(59.0)$ & $34(41.5)$ & 6.355 & .012 \\
\hline Relief from negative emotion & $51(36.7)$ & $27(32.9)$ & 0.320 & .572 \\
\hline Feelings of excitement & $56(40.3)$ & $27(32.9)$ & 1.192 & .275 \\
\hline Passing time & $49(35.3)$ & $42(51.2)$ & 5.429 & .020 \\
\hline
\end{tabular}

TABLE 4. Gender Differences in Variables Associated With the Level of Addiction to Online Gaming (CIAS Scores) in Multiple Linear Regression

\begin{tabular}{lrrrrrrr}
\hline & \multicolumn{3}{c}{ Male } & & \multicolumn{3}{c}{ Female } \\
\cline { 2 - 4 } \cline { 6 - 7 } & \multicolumn{1}{c}{$\boldsymbol{\beta}$} & $\boldsymbol{t}$ & $\boldsymbol{c}$ & & \multicolumn{1}{c}{$\boldsymbol{\beta}$} & \multicolumn{1}{c}{$\boldsymbol{t}$} & $\boldsymbol{p}$ \\
\hline Age & 0.197 & 2.477 & .015 & & 0.076 & 0.655 & .514 \\
RSES scores & -0.188 & -2.312 & .022 & & -0.117 & -0.994 & .324 \\
Daily life satisfaction level & -0.187 & -2.177 & .031 & & -0.129 & -1.036 & .303 \\
Numbers of stressors & 0.138 & 1.621 & .107 & & 0.062 & 0.508 & .613 \\
Online gaming at home & 0.075 & 0.938 & .350 & -0.136 & -1.181 & .241 \\
$F$ value & 6.794 & & & & 1.408 & & \\
$p$ value of $F$ & $<0.001$ & & & & 0.231 & & \\
$\mathrm{R}^{2}$ & 0.205 & & & 0.085 & & \\
\hline
\end{tabular}

female Taiwanese adolescents often receive more family supervision than males, which may prevent females from spending as much time on online gaming.

Depression has been found to be more strongly associated with substance addiction among females than among males (Clark et al., 1997). Female substance abusers also tend to be at a higher risk for relapse when experiencing unpleasant emotions (Rubin et al., 1996). However, in the present study, females did not have a higher tendency than males to report playing online games for the purpose of relieving negative emotions.

The present study also found that male adolescents with lower self-esteem and lower daily life satisfaction are more easily addicted to playing online games. The study of Arm- strong et al. (2000) also confirmed the negative correlation between Internet addiction and self-esteem. In addition, the study of Zullig et al. (2001) found that the early onset of substance use is associated with lower levels of life satisfaction. Online games provide players with activities in which they can feel more confident and to which they can escape from a reality they may find dissatisfying. Evaluation of self-esteem and life satisfaction is important in cases of Internet addiction. Special strategies should be implemented to prevent adolescent addiction to online gaming, especially for older males with lower self-esteem and lower daily life satisfaction. Providing resources to help these adolescents manage low self-esteem and life frustration may prevent them from escaping to online gaming. 
More and more attention has been drawn to the need for diagnostic criteria for Internet addiction. Several researchers have attempted to formulate diagnostic criteria according to the core symptoms of other addictive disorders, including substance dependence and pathological gambling (Beard and Wolf, 2001; Griffiths, 1996; Young, 1998). Before constructing specific diagnostic criteria, it would be practical to measure levels of addiction to Internet use with a multidimensional and continuous questionnaire such as the CIAS used in the present study.

The five independent variables examined in the present study could account for only $20.5 \%$ of the variance in addiction to online gaming among males and $8.5 \%$ among females, indicating that other variables must be influencing online gaming addiction. Further study of other factors such as family interaction, personal characteristics, and their relationships to online gaming addiction is needed. The crosssectional research design of the present study could not determine the causal relationships between Internet addiction and these significantly related variables. Besides, the adolescents without experience of online gaming are not included in the analysis of gender differences in this study. Whether the similar patterns of gender differences would emerge in the group of adolescents is unknown and needs to be studied further.

\section{CONCLUSION}

The present study found that online gaming is more prevalent among male adolescents than among females, and that addiction to online gaming is more likely among males than females. Gender differences were also noted in the motives for online gaming. Older age, lower self-esteem, and lower daily life satisfaction were associated with more severe online gaming addiction among males, but not among females. Gender differences must be considered when developing strategies to prevent addiction to online gaming. Males with lower self-esteem and lower daily life satisfaction should receive increased attention because of their higher tendency to become addicted to online gaming.

\section{REFERENCES}

American Psychiatric Association (1994) Diagnostic and Statistical Manual of Mental Disorders (4th ed). Washington DC: American Psychiatric Publishing, Inc.

Armstrong L, Phillips JG, Saling LL (2000) Potential determinants of heavier Internet usage. Int J Hum Comput Stud. 53:537-550.

Beard KW, Wolf EM (2001) Modification in the proposed diagnostic criteria for Internet addiction. Cyberpsychol Behav. 4:377-383.

Boyle MH, Offord DR (1986) Smoking, drinking and use of illicit drugs among adolescents in Ontario: Prevalence, patterns of use and sociodemographic correlates. Can Med Assoc J. 135:1113-1121.

Bukstein OG, Glancy LJ, Kaminer Y (1992) Patterns of affective comorbidity in a clinical population of dually diagnosed adolescent substance abusers. J Am Acad Child Adolesc Psychiatry. 31:1041-1045.
Chen SH, Weng LC, Su YJ, Wu HM, Yang PF (2003) Development of Chinese Internet Addiction Scale and its psychometric study. Chin J Psychol. 45:279-294.

Clark DB, Pollock N, Bukstein OG, Mezzich AC, Bromberger JT, Donovan JE (1997) Gender and comorbid psychopathology in adolescents with alcohol dependence. J Am Acad Child Adolesc Psychiatry. 36:1195-1203.

Clayton S (1991) Gender differences in psychosocial determinants of adolescent smoking. J Sch Health. 61:115-120.

Coffey C, Carlin JB, Lynskey M, Li N, Patton GC (2003) Adolescent precursors of cannabis dependence: findings from the Victorian Adolescent Health Cohort Study. Br J Psychiatry. 182:330-336.

Dawson DA, Archer L (1992) Gender differences in alcohol consumption: Effects of measurement. Br J Addict. 87:119-123.

Emery EM, McDermott RJ, Holcomb DR, Marty PJ (1993) The relationship between youth substance use and area-specific self-esteem. J Sch Health. 63:224-228.

Ensminger ME, Brown CH, Kellam SG (1984) Social control as an explanation of sex differences in substance use among adolescents. NIDA: Res Monogr. 49:296-304.

Greenfield DN (1999) Psychological characteristics of compulsive Internet use: A preliminary analysis. Cyberpsychol Behav. 2:403-412.

Griffin ML, Weiss RD, Mirin SM, Lange U (1989) A comparison of male and female cocaine abusers. Arch Gen Psychiatry. 46:122-126.

Griffiths M (1996) Nicotine, tobacco and addiction. Nature. 384:18.

Hawkins JD, Catalano RF, Miller JY (1992) Risk and protective factors for alcohol and other drug problems in adolescence and early adulthood: Implications for substance abuse prevention. Psychol Bull. 112:64-105.

Inciardi JA, Lockwood D, Pottieger AE (1993). Women and Crack-Cocaine. New York: McMillian Publishing Co.

Jenks RJ (1994) Smoking and satisfaction and motivations: A comparison of men and women. J Soc Psychol. 134:847-849.

Kreek MJ, Koob GF (1998) Drug dependence: Stress and dysregulation of brain reward pathways. Drug Alcohol Depend. 51:23-47.

Lin SSJ, Tsai CC (2002) Sensation seeking and Internet dependence of Taiwanese high school adolescents. Comput Hum Behav. 18:411-426.

Moon DG, Hecht ML, Jackson KM, Spellers RE (1999) Ethnic and gender differences and similarities in adolescent drug use and refusals of drug offers. Subst Use Misuse. 34:1059-1083.

Newcomb MD, Chou CP, Bentler PM, Huba GJ (1988) Cognitive motivations for drug use among adolescents: Longitudinal tests of gender differences and predictors of change in drug use. J Counsel Psychol. 35:426-438.

Rosenberg M (1965). Society and the Adolescent Self-Image. New Jersey: Princeton University Press.

Rubin A, Stout RL, Longabaugh R (1996) Gender differences in relapse situations. Addiction. 91(suppl):S111-S120.

Wallace JMJr. , Bachman JG, O’Malley PM, Schulenberg JE, Cooper SM, Johnston LD (2003) Gender and ethnic differences in smoking, drinking and illicit drug use among American 8th, 10th and 12th grade students, 1976-2000. Addiction. 98:225-234.

Whang LS, Lee S, Chang G (2003) Internet over-users' psychological profiles: A behavior sampling analysis on Internet addiction. Cyberpsychol Behav. 6:143-150.

Wilsnack RW, Vogeltanz ND, Wilsnack SC, Harris TR, Ahlstrom S, Bondy S, Csemy L, Ferrence R, Ferris J, Fleming J, Graham K, Greenfield T, Guyon L, Haavio-Mannila E, Kellner F, Knibbe R, Kubicka L, Loukomskaia M, Mustonen H, Nadeau L, Narusk A, Neve R, Rahav G, Spak F, Teichman M, Trocki K, Webster I, Weiss S (2000) Gender differences in alcohol consumption and adverse drinking consequences: Cross-cultural patterns. Addiction. 95:251-265.

Young KS (1998) Internet addiction: The emergence of a new clinical disorder. Cyberpsychol Behav. 1:237-244.

Zullig KJ, Valois RF, Huebner ES, Oeltmann JE, Drane JW (2001) Relationship between perceived life satisfaction and adolescents' substance abuse. J Adolesc Health. 29:279-288. 